\title{
Using Publicized Information to Determine the Sustainable Development of 3-PL Companies
}

\author{
Kris M.Y. Law, School of Engineering, Deakin University, Australia \\ College, Velenje, Slovenia \\ (iD) https://orcid.org/0000-0002-8136-9592 \\ Andrew W. H. Ip, University of Saskatchewan, Canada \\ iD https://orcid.org/0000-0001-6609-0713
}

Kristijan Breznik, International School for Social and Business Studies, Celje, Slovenia \& Environmental Protection

\begin{abstract}
Sustainability issues have been seen as a promising paradigm for achieving a better future. Firms in the logistics service sector are still lacking clear value propositions on sustainable development. While many organizations publish their mission statements publicly as kinds of public information, reviewing mission statements is an appropriate means to evaluate an organization's strategy. This study focuses on the public information such as mission statements of the top 50 global 3-PL companies and the relevant sustainable development. A comprehensive content analysis identified four major content dimensions of mission statements relating to sustainability development. The dimensions are driving forces, approaches, responsibility to stakeholders, and competitive values. This paper offers a good methodological reference for researchers or practitioners managing the public information of organizations. Network analysis reveals that the location of companies has a limited effect on their mission and strategy as they all provide global service.
\end{abstract}

\section{KEYWORDS}

Effective Information Management System, Mission Statements, Network Analysis, Public Information, Sustainability, Text Analysis

\section{INTRODUCTION}

Third-Party Logistics (3PL) firms, are one kind of logistics services providers who manage, control, and deliver logistics activities on behalf of shippers (Hertz \& Alfredsson, 2003). They provide integrated services to their customers that allows them to outsource their supply chain management functions. Emphasizing on core-competencies and re-engineering efforts in the supply chain of various industries, 3PL firms are facing a number of challenges. These challenges include competitiveness in the market, social responsibilities relating to environmental issues, and increasing customer demands.

DOI: 10.4018/JGIM.20210101.oa1

This article published as an Open Access article distributed under the terms of the Creative Commons Attribution License (http://creativecommons.org/licenses/by/4.0/) which permits unrestricted use, distribution, and production in any medium, provided the author of the original work and original publication source are properly credited. 
Over the last few decades, sustainable development is seen as a promising paradigm for achieving a better future, and has gained increasing interest from the business sectors, including the logistics services industry (Evangelista et al., 2018; Law \& Gunasekaran, 2012). Environmental aspects, which are within the scope of sustainability, have been studied among logistics companies, as well 3PL companies (Herold \& Herold, 2018).

Sustainable development (SD) involves the integrative approaches addressing environmental sustainability while ensuring social and economic prosperity at the societal level (Khalili et al., 2015). The sustainable development necessitates the set of visions and policies, for building the methodological tools and applicable procedures (Almeida et al., 2015; Haes et al., 2019).

While many organizations publish their mission statement publicly as kinds of public information, reviewing mission statements is an appropriate means to evaluate an organization's strategy (Bart, 2007; Bartkus et al., 2004; Bartkus \& Glassman, 2008; Stallworth Williams, 2008) and values (Johnson et al., 2008; Law \& Breznik, 2018; Taghi Alavi \& Karami, 2009; Thompson \& Strickland, 2003). Studies on mission statements in different types of organizations have been carried out (Analoui \& Karami, 2002; Bart, 2007; Law \& Breznik, 2018; Pearce \& David, 1987), however just only a few are focusing on a particular industry (Jandaghi, 2011). Despite the increasing interest toward sustainability issues, studies on the communication of mission statements and the sustainable development strategy of 3PLs, are still missing.

This study focuses on the public information obtained such as mission statements of the top 50 global 3PL companies (in terms of revenue) to identify the gap in the existing literature concerning sustainable development in 3PLs by using a methodological approach based on mission statement. Previous studies on mission statements among companies in other industries indicated that the sampling method used may have limitations which may lead to biased results. Therefore, we set this exploratory study by postulating two research questions:

RQ1: Are third-party logistics companies concerned about sustainability?

RQ2: What are the dimensions relating to sustainability revealed from the mission statements of third-party logistics companies?

The theoretical background of this research is presented in Section 2. It is followed by Section 3 and Section 4 for research methodology and results respectively. The last two sections, 5 and 6 , present the discussion of results and conclusions. Lastly, effective information system is recommended as crucial to facilitation of the sustainable development approaches.

\section{THEORETICAL BACKGROUND}

\subsection{Organization Vision and Mission}

The strategy process is started by visioning (Finkelstein et al., 2006). A vision statement defines the strategic direction and is generally used to drive an organization to gain competitive advantages (Breznik \& Law, 2019; Costanza et al., 2014; Mirvis et al., 2010; Sutcliffe \& Vogus, 2003).

A compelling vision serves as an essential tool for effective communication from top management to reflect the realistic values within an organization (Coulson-Thomas, 1992; Wilson, 1992).

With respect to their sets of values, organizations define their own missions or purposes of existence (Law \& Breznik, 2018). Values are embedded in mission statements (Bourne \& Jenkins, 2013; Dobni et al., 2000; Paarlberg \& Perry, 2007; Porter, 1985), which support the implementation of strategies (Natek \& Lesjak, 2013; Semler, 1997; Tosti \& Jackson, 1994; Wang et al., 2017). Sets of values constitute organizational culture, which are critical resources for organizational sustainability (Bowman, 1984; Child \& Faulkner, 1998; Pandey, 2015), and sustainable competitive advantages for desirable outcome (Malbašić et al., 2016; Noorderhaven et al., 2002). 


\subsection{Sustainability and Organizations}

Sustainability initially referred to environmental concerns, now globally accepted as a term compassing social, ethical and economical issues (Carroll, 1981, 1999; Dow Jones Sustainability Indices I Sustainability Indices, 2018). It is widely accepted that 'development that meets the needs of the present without compromising the ability of future generations to meet their own needs'. Facing multiple challenges in the global competitive market (Law \& Gunasekaran, 2012), including market competition and changing needs of sustainability, more and more organizations have started to align their self-interest with the public good in ways that add value to both the firms and society.

A company has an obligation to provide short-term and long-term value to shareholders and the society, that is, corporate social responsibility (Ashraf et al., 2019; Hutton et al., 2006). Therefore, a clear understanding of the multi-dimensional constructs of sustainability is crucial, for the organizations to achieve a balance between profitability and sustainability (Law \& Gunasekaran, 2012).

\subsection{Factors Affecting Sustainability Strategies}

The strong bonds between corporate social performance and profitability, are indispensable (Ciliberti et al., 2008; Margolis \& Walsh, 2001; Waddock \& Graves, 1997). Balancing business performance and sustainable development is complex and contingent on situational, company- and industry-specific factors. Management's attitude towards the sustainability development is crucial to the adoption of sustainability development strategies (Closs et al., 2008). Top management determines the set of guiding principles, which make an organization have a stronger sense of hard values and be more motivated to make changes (Clifford, 1985; Marz et al., 2003; Quazi \& O’Brien, 2000; Rojšek, 2001).

Regarding the driving factors, Law and Guna (Law \& Gunasekaran, 2012) defined them as internal and external respectively. Corporate governance and stakeholder engagement are the internal determinants while the legal system, cultural and social factors are external determinants. Internally, for organizations to adopt sustainability strategies, a supportive environment is required, where supportive policies, resources and internal infrastructure, and a well-established performance evaluation system is needed (Linton et al., 2007). External factors like local laws and regulations (which can be closely related to environmental issues), market trends (industry specific), social responsibility and competitiveness are considered as factors leading to the operationalization of corporate-sustainability strategies (Aaker, 2001; Becker-Olsen et al., 2006; Fuller \& Ottman, 2004; Law \& Gunasekaran, 2012; O’Brien, 1999).

\subsection{Studies of Mission Statements of Companies}

Mission statements guide the development and implementation of the organizational strategic planning processes and share the organizational beliefs, management perspectives and approaches among employees and other stakeholders (Breznik, 2016; Germain \& Cooper, 1990; Hirota et al., 2010; Lyons \& Sufi, 2003; Palmer \& Short, 2008). Mission statements offer a mediating effect on the organizational performance, by building and identifying the relationships between the stakeholders (Bartkus \& Glassman, 2008; Hirota et al., 2010; Williams Jr et al., 2014). Significantly better performance results were found in those organizations with formal written mission statements (Law \& Breznik, 2018; Taghi Alavi \& Karami, 2009).

Mission statements contain different dimensions, varying among different industries, sectors, segments and geographical regions (Babnik et al., 2014; Desmidt \& Prinzie, 2011; Peyrefitte \& David, 2006). The elements of mission statements, to a certain extent, can be institutionalized, some of which are disclosed in company reports (DiMaggio \& Powell, 1983; Klemm et al., 1991). Analysing the content of mission statements thus provides a useful insight on the key elements that distinguish between effective mission statements and mere mission statements (Breznik \& Rezk, 2017; Darbi, 2012; Desmidt et al., 2011; Duriau et al., 2007).

Over the last few decades, a number of mission statement studies were conducted in various industries or sectors, such as the pharmaceutical industry (Rosenbeck et al., 2010), 
regional segment study (Bartkus et al., 2004), Fortune 1000 companies, hospitals (Bolon, 2005), airlines (Kemp \& Dwyer, 2003; Law \& Breznik, 2018), top 50 US news and world media (Bjelle, 2019; Hong et al., 2010) etc.

A number of factors affect sustainability strategy implementation, internally and externally. Values induced by these factors are therefore rooted in the mindsets of the top management of companies that are keen on adopting sustainability. Top management determines the set of guiding principles, defining the values and making changes (Alnodel et al., 2018; Clifford, 1985; Marz et al., 2003; Quazi \& O'Brien, 2000; Rojšek, 2001). Approaches in adopting sustainability may be also revealed in mission statements, such as supportive policies, resources and internal infrastructure (Linton et al., 2007).

Besides the competitive values, approaches and responsibility, the driving forces of sustainability strategies, like regulations on environmental issues, the external market, society and business objectives are also found in mission statements (Aaker, 2001; Becker-Olsen et al., 2006; Christopher, 2005; Fuller \& Ottman, 2004; Law \& Gunasekaran, 2012).

Despite the increasing interest toward sustainability issues in the logistics sector (Evangelista et al., 2018; Law \& Gunasekaran, 2012), rarely have there been studies regarding how companies are approaching their sustainable development strategy in mission statements, particularly 3PLs. One of these studies (Herold et al., 2017) examined mission statements of three 3PL providers (DHL, Fedex and UPS) to investigate carbon disclosure strategies. Duygulu et al. (Duygulu et al., 2016), identified that survival, growth and profit are the most frequently observed mission components, which reflect the significance of sustainability for SMEs in Turkey.

\subsubsection{Third Party Logistics and Sustainability}

Third party logistics (3PL) providers provide the integration of warehousing, transportation, distribution and freight consolidation services that can be customized and scaled to customers' needs for various market conditions, in order to fit the structure and the requirements of the client company. 3PL services can be classified in accordance with their functions, including warehousing and distribution, transportation and information technology (IT) services. In the growing supply chain focus, greater emphasis on core-competencies and re-engineering efforts are the key factors driving the 3PL industry to grow and expand (Cooper et al., 1998; Karia et al., 2015). Currently, the 3PL sector is dominated by about 50 of the largest firms (in terms of sales revenues), which are mainly based in post-industrial regions, such as the U.S., Europe and Asia. The top 3PL providers are scaled by geographical coverage, IT competencies and advanced processes, which differentiate them from rivals and create threshold levels that block small competitors from overtaking them (Armstrong \& Associates, Inc., 2015). The global 3PL market generated US\$750.7 billion in 2014 and grew further in 2015.

3PL firms accommodate the demand for outsourcing a firm's logistics functions to an external party, that allows firms to focus on the core business for operational efficiency and flexibility (Çatay \& Göl, 2007; Christopher, 1993; Nadarajah, 2015; Persson \& Virum, 2001).

Factors in employing 3PL providers are economic and strategic (Zhang \& Hung Lau, 2006), which are highly relevant to the major objectives of sustainability. Economically, 3PL providers help firms to reduce costs and increase efficiency; strategically, outsourcing logistics can help enhance flexibility and performance (Brewer et al., 2013).

In order to remain competitive in the market and to sustain the business when facing a number of challenges due to globalization, 3PL companies are required to meet increasing demand and allocate resources in a more efficient and economical manner (Christopher, 2005). The impact of digitalization has placed significant impacts on the service industries, such as 3PLs (Hofmann \& Osterwalder, 2017). The new disruptive business models offered by competitors, and advancements in technologies, bring suppliers and customers together, and increasingly challenge 3PLs. Not only are 3PL providers concerned about business services and quality, but issues related to social and 
environmental sustainability are also important. The 3PL service is greatly dependent on transport vehicles (where carbon emission is a concern) and sufficient employees being hired for the 3PL activities (Jung, 2017). Therefore, social responsibility and environmental responsibility, which are the integral components of sustainability, are equally important in business sustainability from the 3PL providers' viewpoint.

Sustainability strategies are therefore welcomed by 3PL firms to enable them to excel in 'services' and 'competitive operational performance' (Berglund et al., 2000; Kumar, 2008; Li, 2014).

\section{METHODOLOGY}

Mission statements of the targeted 3PL firms were retrieved in text format from the companies' websites or annual reports. Content analysis was employed to extract the most important words (keywords) from the retrieved mission statements. Keywords were further analysed using descriptive statistics and network analysis. In Figure 1 flow chart showing the methods is provided.

Figure 1. Flow chart of methods used

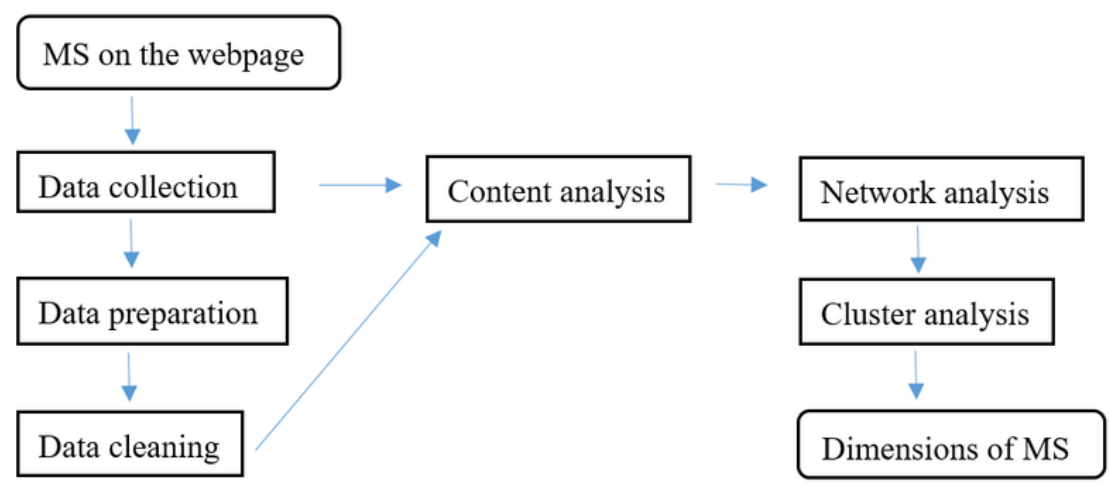

\subsection{Data Collection}

A list of the targeted global 3PL firms was obtained from Armstrong \& Associates, Inc. (A\&A) ${ }^{1}$ which is a leading 3PL market research and consulting company that provides updated 3PL information and databases. The ranking of the 50 top-performing firms was selected based on their annual revenue in the fiscal year 2015.

Mission statements of the targeted organizations were listed with details such as, name, year of founded, location (with region and country), annual revenue, number of employees, from the companies' publicized websites or their annual reports.

\subsubsection{The Dataset}

It is critical for the classification procedure to be reliable in the sense of being consistent, whereby different people code the same text in the same manner (Weber, 1990). To increase the validity and reliability of this research, the literature review helps in obtaining a thorough summary on the findings of all studied articles and from various recognized academic sources.

In Table 1, the demographics of the top fifty (50) 3PL companies from 4 regions (i.e. US, Asia, Europe and Australia) are shown. The largest number of employees is around 440,000 in UPS Supply Chain Solutions, while the least number of employees is around 600 in Transplace. 
Table 1. Demographics of the sample

\begin{tabular}{|c|c|}
\hline Region & Number of Companies \\
\hline United States & 18 \\
\hline Asia & 12 \\
\hline Europe & 19 \\
\hline Australia & 1 \\
\hline \multicolumn{2}{|c|}{ Number of Employees } \\
\hline Less than 5,000 & 7 \\
\hline More than 5,000 and less than 30,000 & 29 \\
\hline More than 30,000 and less than 100,000 & 9 \\
\hline Over 100,000 & 5 \\
\hline \multicolumn{2}{|c|}{ Year the Company Established } \\
\hline $1800-1899$ & 6 \\
\hline 1900-1999 & 38 \\
\hline$>2000$ & 6 \\
\hline \multicolumn{2}{|c|}{ Revenue of Company (in millions USD) } \\
\hline $1,000-3,999$ & 26 \\
\hline $3,000-5,999$ & 14 \\
\hline $6,000-7,999$ & 6 \\
\hline$>8,000$ & 4 \\
\hline
\end{tabular}

\subsubsection{Data Preparation}

To prepare an optimum data set for further analysis, the spelling of every word in the mission statements was thoroughly checked. A computer algorithm was used to remove some irrelevant words such as 'the', 'a', 'some' etc. We were left with 623 words in 50 mission statements.

Irrelevant stop words in the mission statements were then removed from the mission statement. The next step was to combine the synonyms or words with similar meaning, for instance, company, companies and organization. Besides, the punctuation in every mission statement was removed and all words were changed to small letters. The aforementioned steps are crucial for further analysis. Words that satisfied all criteria and were not excluded from the mission statements are called the keywords. In the data preparation phase, we mainly used program R ( $R$ : The R Project for Statistical Computing, 2018) and its library tm (Feinerer et al., 2018).

\subsection{Data Analysis}

First, we calculated occurrence frequencies and identified keywords that were related to sustainable development. There was no objective criterion for this problem. Similar to Serenko (Serenko, 2013), we followed our theoretical understanding of the 'sustainability' concept. Then, we built a network of keywords. By definition, every (social) network consists of two items. First item are the actors/ entities in the network which are presented by nodes. In our case, keywords form the set of all entities. The second item involves relations defined on the set of entities and presented by ties among them. We defined relation as co-occurrence of two keywords in the same mission statement. In this way, the relation and consequently the network are undirected and weighted by the number of the 
co-occurrences. Moreover, the problem can be analysed from the opposite perspective, the mission statements (and companies) can form entities and the co-occurrence of keywords can be defined as a relation. Similar to the previous option, the obtained network is undirected and weighted. The advanced network analytic techniques used in the paper are described where appropriate. Algorithms for generating the networks were written in R ( $R$ : The $R$ Project for Statistical Computing, 2018). Network analysis was performed in Pajek (Batagelj \& Mrvar, 2004) which is a program for analysis and visualization of (large) networks.

\section{RESULTS}

After the cleaning process, we were left with 269 keywords. Among them, we identified 118 keywords (43.87\% of all keywords) that are related to the three core dimensions in sustainability (social, environmental, business). For example, 'business' refers to the services or activities involving 3PL services, and the business goals concerned in sustaining the business; 'transport' refers to the core business activities of 3PLs, requiring vehicles and employees, are related to environmental concerns as well as social concerns; 'company' refers to a single 3PL firm that has its unique mission and strategy; and 'global' refers to both the global challenges faced by 3PLs and also their sustainable strategies to go 'global'.

The top 26 most frequent keywords (keywords which appear in at least 7 mission statements) are presented in Table 2. Keywords that are related to sustainable development are displayed in italics.

There are $69.23 \%$ of all keywords among top 26 that are related to sustainable development. 'Client' accounts for the highest frequency which means this word appears in 40 out of 50 mission statements from the 3PL companies. Only one other keyword, namely 'best', appear in more than half the mission statements.

\subsection{Network of Keywords}

A network of keywords consists of keywords (actors), and co-occurrence of keywords in the same mission statement is presented as a relation. Therefore, two keywords are linked if they occur together in (at least one) mission statement. There are 5914 undirected links (edges) in the network of keywords. The density of the network is 0.1641 , which means that approximately $16 \%$ of all possible links in the network are established.

The average degree of a keyword is 43.97 , i.e. on average a keyword in the network is linked with almost 44 other keywords (out of 268 possible). Standard network centrality measures 26 of the most frequent keywords as displayed in Table 3. The concept of centrality is closely related to the concept of importance in a network. The word 'client' turned out to be the most important in the keywords network. Besides 'client', the words 'best', 'logistics', 'global', 'serve' and 'provide' also clearly stand out according to the other keywords.

Weights on the links count number of common mission statements among adjacent keywords. Not surprisingly, the strongest link connects the keywords 'client' and 'best'. The weight on the link is 22 which means that they appear together in 22 mission statements (out of 50). Other strong links between keywords are presented in Table 3.

To find the nodes in the keywords network that are tightly connected, we used the method of cores, more precisely k-cores (De Nooy et al., 2018). By definition, a k-core is a maximal subnetwork in which each node has at least degree $\mathrm{k}$ within the subnetwork. After preliminary analysis, we set a number $\mathrm{k}$ to 50 . In other words, each keyword in our 50-core has at least 50 links to other keywords inside this 50-core.

To remove less important links in the 50-core network, we applied the PathFinder algorithm (Chaomei Chen \& Morris, 2003). The PathFinder algorithm has two important properties. On the one hand, it preserves the connectivity and on the other hand it provides the skeleton of the network. 
Table 2. Top 26 most frequent words in mission statements of 3PL companies

\begin{tabular}{|c|c|c|c|c|c|c|c|}
\hline Rank & Word & Frq & Frq in $\%$ & Degree & Closeness & Betweenness & Eingenvalue \\
\hline 1 & client & 40 & 80 & 233 & 0.8845 & 0.1318 & 0.3646 \\
\hline 2 & best & 27 & 54 & 202 & 0.8024 & 0.0839 & 0.2949 \\
\hline 3 & logistics & 24 & 48 & 182 & 0.7571 & 0.0453 & 0.2760 \\
\hline 4 & global & 22 & 44 & 181 & 0.7549 & 0.0545 & 0.2395 \\
\hline 5 & serve & 21 & 42 & 176 & 0.7444 & 0.0396 & 0.2484 \\
\hline 6 & provide & 17 & 34 & 162 & 0.7166 & 0.0436 & 0.2149 \\
\hline 7 & deliver & 15 & 30 & 127 & 0.6553 & 0.0195 & 0.1572 \\
\hline 8 & solution & 15 & 30 & 122 & 0.6473 & 0.0154 & 0.1670 \\
\hline 9 & supplier & 15 & 30 & 146 & 0.6872 & 0.0225 & 0.1758 \\
\hline 10 & value & 12 & 24 & 140 & 0.6768 & 0.0195 & 0.1718 \\
\hline 11 & innovation & 11 & 22 & 126 & 0.6537 & 0.0163 & 0.1457 \\
\hline 12 & safe & 10 & 20 & 105 & 0.6218 & 0.0122 & 0.1158 \\
\hline 13 & support & 10 & 20 & 105 & 0.6218 & 0.0128 & 0.1129 \\
\hline 14 & transport & 10 & 20 & 112 & 0.6321 & 0.0127 & 0.1186 \\
\hline 15 & business & 9 & 18 & 111 & 0.6306 & 0.0106 & 0.1261 \\
\hline 16 & chain & 9 & 18 & 103 & 0.6189 & 0.0085 & 0.1068 \\
\hline 17 & company & 9 & 18 & 142 & 0.6802 & 0.0282 & 0.1193 \\
\hline 18 & commitment & 8 & 16 & 82 & 0.5903 & 0.0058 & 0.1003 \\
\hline 19 & manage & 8 & 16 & 110 & 0.6291 & 0.0141 & 0.0945 \\
\hline 20 & people & 8 & 16 & 96 & 0.6091 & 0.0079 & 0.1048 \\
\hline 21 & achieve & 7 & 14 & 115 & 0.6366 & 0.0158 & 0.1007 \\
\hline 22 & create & 7 & 14 & 96 & 0.6091 & 0.0105 & 0.0855 \\
\hline 23 & focus & 7 & 14 & 92 & 0.6036 & 0.0054 & 0.0968 \\
\hline 24 & need & 7 & 14 & 90 & 0.6009 & 0.0042 & 0.1080 \\
\hline 25 & operate & 7 & 14 & 107 & 0.6247 & 0.0092 & 0.0918 \\
\hline 26 & quality & 7 & 14 & 87 & 0.5969 & 0.0052 & 0.0936 \\
\hline
\end{tabular}

Keywords were further clustered by using the Louvain method for community detection (Blondel et al., 2008). This simple method is implemented in two steps, and repeated iteratively until the best solution is reached. In the first step, small communities are detected locally, it is followed by the second step in which the algorithm aggregates nodes belonging to the same community. In a new network, communities represent nodes. In the rest of this paper, the term 'cluster' is replaced by term 'community'.

The Network obtained using above described methods is presented in Figure 2. Sustainability keywords are displayed by circles, and other keywords are displayed by squares.

From Figure 2, the keywords are clustered into four groups, all presenting some values relating to sustainability of the companies being studied. A significant number of keywords in each cluster relate to sustainability development aspects, such as 'driving forces', 'approaches for sustainability development', 'responsibility to stakeholders' and 'competitive values in sustainability'. 
Table 3. Most frequent links with adjacent words and their ranks

\begin{tabular}{|l|l|l|l|l|}
\hline \multicolumn{1}{|c|}{ Word1 } & \multicolumn{1}{|c|}{ Rank of Word1 } & Word2 & Rank of Word2 & Weight on the Link \\
\hline client & 1 & best & 2 & 22 \\
\hline client & 1 & logistics & 3 & 19 \\
\hline client & 1 & global & 4 & 16 \\
\hline client & 1 & serve & 5 & 16 \\
\hline client & 1 & provide & 6 & 14 \\
\hline client & 1 & deliver & 7 & 14 \\
\hline best & 2 & logistics & 3 & 14 \\
\hline best & 2 & serve & 5 & 14 \\
\hline client & solution & 8 & 13 \\
\hline client & 1 & suplier & 9 & 13 \\
\hline logistics & 1 & global & 4 & 13 \\
\hline logistics & 2 & serve & 5 & 13 \\
\hline
\end{tabular}

Figure 2. The core-network of keywords obtained with PathFinder algorithm and Louvain method for community detection

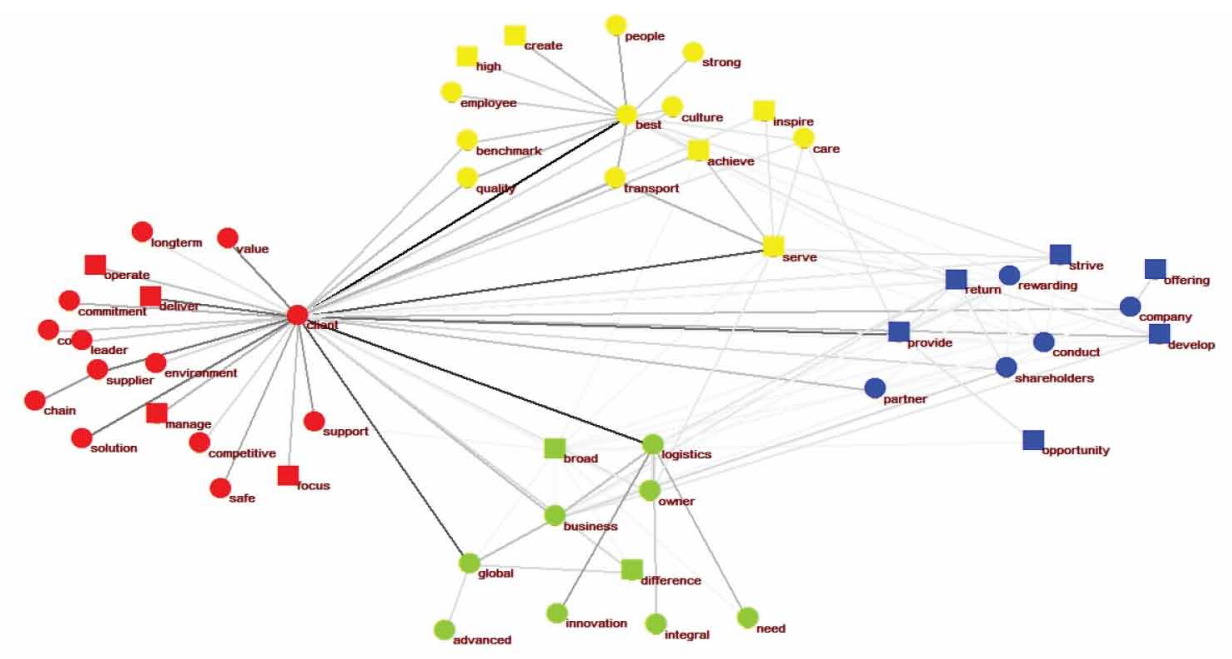

\subsubsection{Network of Companies}

In this section, we reversed the network idea and built a network of 3PL companies where the relation is determined by common keywords that occur in adjacent companies. In this way, the network of 3PL companies determine an undirected and weighted network. The weight on the link between two adjacent companies is obtained as the co-occurrence of keywords in their mission statements. Figure 3 presents a network of mission statements with the regional relationship and revenue. The size of the circle represents the revenue of a company. The larger the size of the circle, the higher the revenue of the company. Links between each company are formed by the number of the same words shared by the mission statement of each company. The higher the number of same words, the thicker link between the companies. For instance, if a keyword 'client' appears in two companies, 


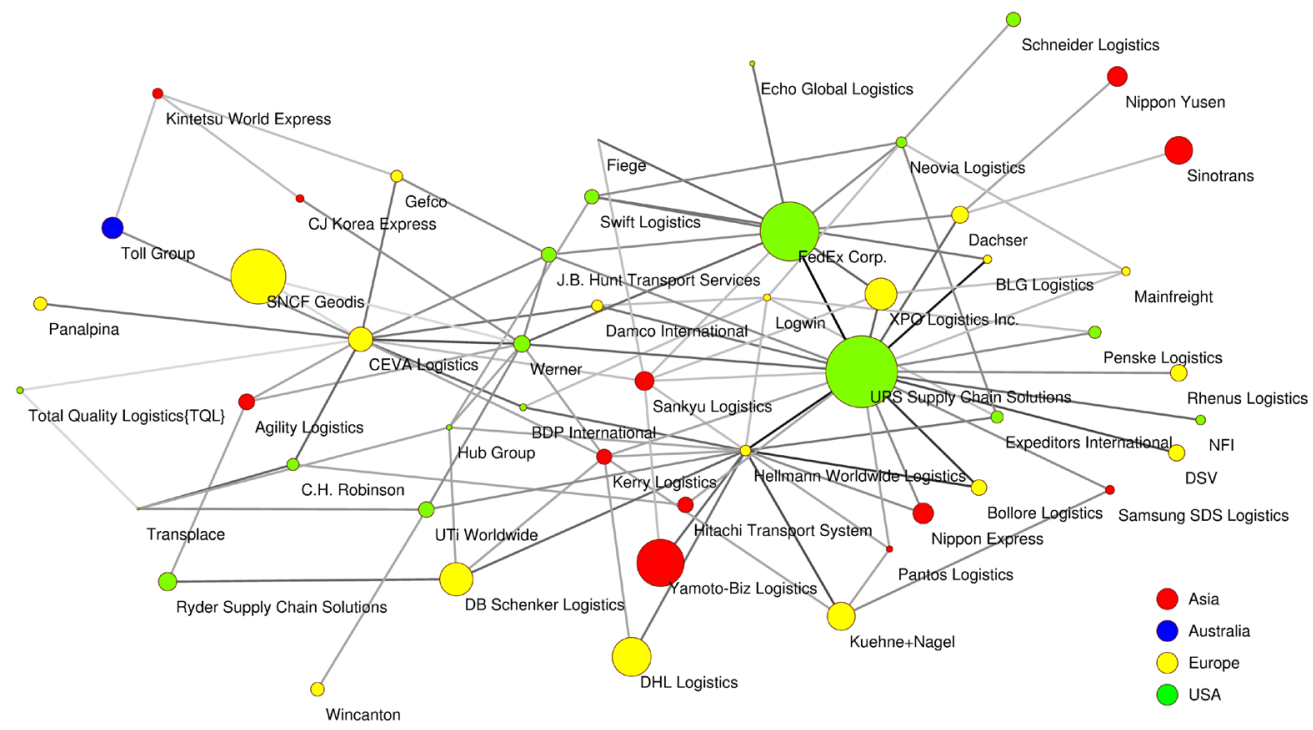

there will be a link between them. Different colours of the circle represent the continent where the companies belong to.

\section{DISCUSSION}

From Figure 2 (Section 3), we can identify four dimensions of 3PL companies mission statements, with reference to sustainability development. Table 4 shows a summary of the result and the interpretation of each cluster.

The words in Table 4 contains the core words, which are related to sustainability development in the mission statements of global 3PL companies.

\subsection{The Identified Core Dimensions}

\subsubsection{Driving Forces (Red)}

From Figure 2, cluster one contains the words: 'commitment', 'long-term', 'client', 'value', 'supplier', 'solution'. It stresses the possible driving forces of 3PL companies to adopt sustainability development. Companies are driven by their 'commitment' towards social responsibility to the public, to their

Table 4. Summary of network results

\begin{tabular}{|l|l|l|}
\hline Cluster & \multicolumn{1}{|c|}{ Interpretation } & \multicolumn{1}{c|}{ Words in the Cluster Relating to Sustainability Development } \\
\hline 1 & Driving forces (Red) & Commitment, long-term, competitive, client, supplier, value, solution \\
\hline 2 & Approaches (Yellow) & $\begin{array}{l}\text { Benchmark, create, high, best, strong, quality, culture, employee, } \\
\text { transport }\end{array}$ \\
\hline 3 & $\begin{array}{l}\text { Responsibility to stakeholders } \\
\text { (Blue) }\end{array}$ & Partner, shareholder, company, conduct, rewarding \\
\hline 4 & Competitive values (Green) & Innovation, integral, global, advanced, logistics, need \\
\hline
\end{tabular}


'clients' and as well to the society. The words 'long-term', 'value' and 'solution' represent their need to call for long-term solutions in sustainable development aspects, such as environmental, societal and their own development concerns.

\subsubsection{Approaches of Sustainability Development (Yellow)}

Cluster two consists of the words 'benchmark', 'create', 'high', 'best', 'strong', 'quality', 'culture', 'employee' and 'transport'. It describes the various approaches adopted by the companies. The words 'best', 'quality' and 'high' label the expected standard and desired quality of the logistics services to be delivered. The word 'benchmark' incorporates the idea of globalization by benchmarking with other competitors. Besides setting high aims in providing quality services as part of the sustainability approach, the keywords 'culture' and 'employee' show that 3PL firms also emphasize on the culture built within organizations, among employees.

\subsubsection{Responsibility to Stakeholders (B/ue)}

The third cluster includes the words 'partner', 'shareholder', 'company', 'conduct', and 'rewarding'. It identifies the companies' concerns in being responsible to their stakeholders. 'Conduct' and 'rewarding' emphasize the companies' focus on meeting the expectations of its stakeholders, which are crucial for companies to maintain a long-standing relationship with their stakeholders.

\subsubsection{Competitive Values (Green)}

The fourth cluster includes the words 'innovation', 'integral', 'global', 'advanced', 'logistics' and 'need'. These words incorporate the idea of the competitive advantages or values of a company (Pearce \& David, 1987). Services and performance through innovation or advanced logistics solutions meeting clients' 'needs' are two important factors that influence the success of the 3PL companies. The words 'global', 'advanced' reveal the connection between mission statements and business planning in identifying business strengths (King et al., 2014).

\subsection{Network of Mission Statement According to Regional Relationship}

The network in Figure 3, presents the relationship of the mission statement with regional affiliation. There is no specific pattern of the relationship between regions and mission statement. The location of a global company has a limited effect on their mission and strategy as they all provide global services. The larger the size of the circle means the greater the revenue of a company. From the figure above, the 3PL companies in Europe accounts for the majority of highest revenue companies, while the companies in Asia and Australia have relatively lower revenue, and the U.S.A companies are in-between.

\subsection{Sustainability Concerning 3PL Companies and Implications}

Regarding the first research question, study on mission statements reveals that the top 3PL firms are concerned about sustainability (RQ1). The identified keywords from mission statements reflect the values of concern by the top 3PL companies. A significant portion of these values relate to sustainable development. The top 3PL companies are not merely concerned about business performance or profitability, but also about sustainability. These 3PLs contribute to sustainable development through their core business activities, including those connecting to their supply chain partners (Yu et al., 2016).

Values relating to sustainability are identified from the mission statements of 3PLs. These values are further grouped into clusters, which indicate the major dimensions of the strategies. These key dimensions are, namely, the driving forces, approaches, stakeholders and competitive values (RQ2). Driving forces motivate 3PL companies to go for sustainable development (Law \& Gunasekaran, 2012), where various approaches are undertaken. Sustainable development goals are met by adopting supporting approaches (Yu et al., 2016). Responsibility towards various stakeholders determines the approaches of sustainable development. 
Our results confirm that 3PL companies, though with specific industry characteristics, are concerned about sustainability. Though exploratory, the identified dimensions show various sustainability strategies of 3PL companies. Furthermore, sustainability is not limited to 3PL companies in a specific region (Figure 3), as all the sample companies have a global business vision.

\subsubsection{Effective Information Management Facitliting the Sustainable Development as Future Work}

The results imply that sustainability is not just a regional issue of concern to a limited number of 3PL companies, but a goal that most of the top companies are striving for. Companies opting for sustainability can have multiple reasons (driving forces), with different approaches, and with different objectives such as competitive values or responsibilities towards society and their own stakeholders.

To facilite the sustainable development approaches, effective information management is crucial. The features of information management include: the communication between suppliers and customers; the information sharing within an organization for innovation and culture building. An effective information management system can enhance services and performance through innovation or advanced logistics solutions to clients' 'needs' which align with the competitive value dimension containing 'global' and 'advanced' in the mission statements (King et al., 2014).

\section{CONCLUSION}

A comprehensive and thorough content analysis reveals four major content dimensions of mission statements among the top fifty 3PL organizations, relating to sustainability development. The dimensions include 1) driving forces; 2) approaches; 3) responsibility to stakeholders, and 4) competitive values.

Sustainability for both society and environment as well for enterprise require balanced long and shortterm strategies among influential stakeholders (clusters 'driving forces' and 'responsibility to stakeholders').

The process of the sustainable development that aligns the self-interest of the firm with the greater public good and its stakeholders (cluster 'responsibility to stakeholders). Implementing mission statements effectively helps companies to offer high quality transportation services and thus to achieve business sustainability (cluster 'approaches'). Lastly the cluster 'competitive values' indicates the core sustainability values that 3PL firms adopt to stand out themselves out in the competitive market.

This work also has some limitations which can be considered as cornerstones for our work in the future. Firstly, only fifty of the best 3PL companies were included in the study. Secondly, keywords in the paper consisted of only one word. It would be interesting but also very challenging to search for terms consisting more than one word. From our experience analysing mission statements, some organisations even do not differentiate between mission statement and vision (on their website there is just one postulate: 'mission and vision'). As it is known that mission statement is oriented in the present situation of organisation (Who are we?) and vision in the future (What would we like to achieve?). Last but not least, it would be interesting to compare a company's mission to its vision.

\section{AUTHORS CONTRIBUTION}

The order of the authors is arbitrary as all authors evaluate their contributions equal. KL prepared the theoretical part and data collection, KB prepared the methodological part. Other parts were of equal contributions.

\section{FUNDING AGENCY}

Open Access Funding for this article has been provided by IGI Global. 


\section{REFERENCES}

Aaker, D. A. (2001). Developing Business Strategies (6th ed.). Wiley.

Almeida, C. M. V. B., Agostinho, F., Giannetti, B. F., \& Huisingh, D. (2015). Integrating cleaner production into sustainability strategies: An introduction to this special volume. Journal of Cleaner Production, 96, 1-9. doi:10.1016/j.jclepro.2014.11.083

Alnodel, A. A., Elobaid, D. E., Elawady, S. I., \& Alhdaif, S. A. (2018). Business colleges and their community: Content analysis of websites of business colleges in the MENA region. International Journal of Engineering Business Management, 10, 184797901880089. doi:10.1177/1847979018800891

Analoui, F., \& Karami, A. (2002). CEOs and development of the meaningful mission statement. Corporate Governance: The International Journal of Business in Society, 2(3), 13-20. doi:10.1108/14720700210440044

Armstrong \& Associates Inc. (2015, June 22). 3PL Market Analysis 2015. Armstrong \& Associates. https:// www.3plogistics.com/big-deal-2014-3pl-results-and-2015-estimates/

Ashraf, M. M., Razzaque, M. A., Liaw, S.-T., Ray, P. K., \& Hasan, M. R. (2019). Social business as an entrepreneurship model in emerging economy. Management Decision. Advance online publication. doi:10.1108/ MD-04-2017-0343

Babnik, K., Breznik, K., Dermol, V., \& Trunk Širca, N. (2014). The mission statement: Organisational culture perspective. Industrial Management \& Data Systems, 114(4), 612-627. doi:10.1108/IMDS-10-2013-0455

Bart, C. (2007). A comparative analysis of mission statement content in secular and faith-based hospitals. Journal of Intellectual Capital, 8(4), 682-694. doi:10.1108/14691930710830837

Bartkus, B. R., \& Glassman, M. (2008). Do Firms Practice What They Preach? The Relationship Between Mission Statements and Stakeholder Management. Journal of Business Ethics, 83(2), 207-216. doi:10.1007/ s10551-007-9612-0

Bartkus, B. R., Glassman, M., \& McAfee, R. B. (2004). A Comparison of the Quality of European, Japanese and U.S. Mission Statements: A Content Analysis. European Management Journal, 22(4), 393-401. doi:10.1016/j. emj.2004.06.013

Batagelj, V., \& Mrvar, A. (2004). Pajek: Program for analysis and visualization of large networks. Timeshift-The World in Twenty-Five Years: Ars Electronica, 242-251.

Becker-Olsen, K. L., Cudmore, B. A., \& Hill, R. P. (2006). The impact of perceived corporate social responsibility on consumer behavior. Journal of Business Research, 59(1), 46-53. doi:10.1016/j.jbusres.2005.01.001

Berglund, M., Peters, M., \& van Laarhoven, P. (2000). Third-party logistics in Europe - five years later. International Journal of Physical Distribution \& Logistics Management, 30(5), 425-442. doi:10.1108/09600030010336216

Bjelle, S. L. (2019). Auditing Industrial Safety Management: A Case Study. Academic Press.

Blondel, V. D., Guillaume, J.-L., Lambiotte, R., \& Lefebvre, E. (2008). Fast unfolding of communities in large networks. Journal of Statistical Mechanics, 2008(10), P10008. Advance online publication. doi:10.1088/1742$5468 / 2008 / 10 / \mathrm{P} 10008$

Bolon, D. S. (2005). Comparing Mission Statement Content in For-Profit and Not-For-Profit Hospitals: Does Mission Really Matter? Hospital Topics, 83(4), 2-9. doi:10.3200/HTPS.83.4.2-10 PMID:16425696

Bourne, H., \& Jenkins, M. (2013). Organizational Values: A Dynamic Perspective. Organization Studies, 34(4), 495-514. doi:10.1177/0170840612467155

Bowman, E. H. (1984). Content Analysis of Annual Reports for Corporate Strategy and Risk. Interfaces, 14(1), 61-71. doi:10.1287/inte.14.1.61

Brewer, B. L., Ashenbaum, B., \& Carter, J. R. (2013). Understanding the Supply Chain Outsourcing Cascade: When Does Procurement Follow Manufacturing Out the Door? The Journal of Supply Chain Management, 49(3), 90-110. doi:10.1111/jscm.12021 
Breznik, K. (2016). Using social network analysis to identify innovation clusters. International Journal of Innovation and Learning, 19(3), 272. doi:10.1504/IJIL.2016.075654

Breznik, K., \& Law, K. M. Y. (2019). What do mission statements reveal about the values of top universities in the world? The International Journal of Organizational Analysis, 27(5), 1362-1375. doi:10.1108/IJOA-08-2018-1522

Breznik, K., \& Rezk, H. (2017). The mission statements of public research centres in Egypt. World Transactions on Engineering and Technology Education, 15(2), 6.

Carroll, A. B. (1981). Business and society: Managing corporate social performance. Little, Brown.

Carroll, A. B. (1999). Corporate Social Responsibility: Evolution of a Definitional Construct. Business \& Society, 38(3), 268-295. doi:10.1177/000765039903800303

Çatay, B., \& Göl, H. (2007). Third-party logistics provider selection: Insights from a Turkish automotive company. Supply Chain Management, 12(6), 379-384. doi:10.1108/13598540710826290

Chen, C., \& Morris, S. (2003). Visualizing evolving networks: Minimum spanning trees versus pathfinder networks. IEEE Symposium on Information Visualization 2003 (IEEE Cat. No.03TH8714), 67-74. doi:10.1109/ INFVIS.2003.1249010

Child, J., \& Faulkner, D. (1998). Strategies of Cooperation: Managing Alliances, Networks, and Joint Ventures. Oxford University Press.

Christopher, M. (1993). Logistics and competitive strategy. European Management Journal, 11(2), $258-261$. doi:10.1016/0263-2373(93)90049-N

Christopher, M. (2005). Logistics and Supply Chain Management: Creating Value-adding Networks. Pearson Education.

Ciliberti, F., Pontrandolfo, P., \& Scozzi, B. (2008). Logistics social responsibility: Standard adoption and practices in Italian companies. International Journal of Production Economics, 113(1), 88-106. doi:10.1016/j. ijpe.2007.02.049

Clifford, D. (1985). The Winning Performance: How America's High-Growth Midsize Companies Succeed. Bantam.

Closs, D. J., Jacobs, M. A., Swink, M., \& Webb, G. S. (2008). Toward a theory of competencies for the management of product complexity: Six case studies. Journal of Operations Management, 26(5), 590-610. doi:10.1016/j.jom.2007.10.003

Cooper, J., Lieb, R. C., \& Randall, H. L. (1998). The Third-Party Logistics Industry in Europe: Provider Perspectives on the Industry's Current Status and Future Prospects. International Journal of Logistics Research and Applications, 1(1), 9-25. doi:10.1080/13675569808962035

Costanza, R., de Groot, R., Sutton, P., van der Ploeg, S., Anderson, S. J., Kubiszewski, I., Farber, S., \& Turner, R. K. (2014). Changes in the global value of ecosystem services. Global Environmental Change, 26, $152-158$. doi:10.1016/j.gloenvcha.2014.04.002

Coulson-Thomas, C. J. (1992). Quality: Where Do We Go from Here? International Journal of Quality \& Reliability Management, 9(1). Advance online publication. doi:10.1108/02656719210007572

Darbi, W. P. K. (2012). Of Mission and Vision Statements and Their Potential Impact on Employee Behaviour and Attitudes: The Case of A Public But Profit-Oriented Tertiary Institution. Academic Press.

De Nooy, W., Mrvar, A., \& Batagelj, V. (2018). Exploratory social network analysis with Pajek. Cambridge University Press. doi:10.1017/9781108565691

Desmidt, S., Prinzie, A., \& Decramer, A. (2011). Looking for the value of mission statements: A metaanalysis of 20 years of research. Management Decision, 49(3), 468-483. Advance online publication. doi: $10.1108 / 00251741111120806$ 
Desmidt, S., \& Prinzie, A. A. (2011). The Organization's Mission Statement: Give Up Hope or Resuscitate? A Search for Evidence-Based Recommendations. In Organization Development in Healthcare: Conversations on Research and Strategies (Vol. 10, pp. 25-41). Emerald Group Publishing Limited. doi:<ALIGNMENT.qj $></$ ALIGNMENT > 10.1108/S1474-8231(2011)0000010008

DiMaggio, P. J., \& Powell, W. W. (1983). The Iron Cage Revisited: Institutional Isomorphism and Collective Rationality in Organizational Fields. American Sociological Review, 48(2), 147-160. doi:10.2307/2095101

Dobni, D., Ritchie, J. R. B., \& Zerbe, W. (2000). Organizational Values: The Inside View of Service Productivity. Journal of Business Research, 47(2), 91-107. doi:10.1016/S0148-2963(98)00058-7

Dow Jones Sustainability Indices | Sustainability Indices. (2018). https://www.sustainability-indices.com/aboutus/dow-jones-sustainability-indices.jsp

Duriau, V. J., Reger, R. K., \& Pfarrer, M. D. (2007). A Content Analysis of the Content Analysis Literature in Organization Studies: Research Themes, Data Sources, and Methodological Refinements. Organizational Research Methods, 10(1), 5-34. doi:10.1177/1094428106289252

Duygulu, E., Ozeren, E., Işıldar, P., \& Appolloni, A. (2016). The Sustainable Strategy for Small and Medium Sized Enterprises: The Relationship between Mission Statements and Performance. Sustainability, 8(7), 698. doi:10.3390/su8070698

Evangelista, P., Santoro, L., \& Thomas, A. (2018). Environmental Sustainability in Third-Party Logistics Service Providers: A Systematic Literature Review from 2000-2016. Sustainability, 10(5), 1627. doi:10.3390/su10051627

Feinerer, I., Hornik, K., Software, A., \& Ghostscript, I. (2018). tm: Text Mining Package (Version 0.7-5) [Computer software]. https://CRAN.R-project.org/package $=$ tm

Finkelstein, S., Harvey, C., \& Lawton, T. (2006). Breakout Strategy: Meeting the Challenge of Double-Digit Growth (1st ed.). McGraw-Hill Education.

Fuller, D. A., \& Ottman, J. A. (2004). Moderating unintended pollution: The role of sustainable product design. Journal of Business Research, 57(11), 1231-1238. doi:10.1016/S0148-2963(02)00446-0

Germain, R., \& Cooper, M. B. (1990). How a customer mission statement affects company performance. Industrial Marketing Management, 19(1), 47-54. doi:10.1016/0019-8501(90)90027-S

Haes, S. D., Huygh, T., Joshi, A., \& Caluwe, L. (2019). National Corporate Governance Codes and IT Governance Transparency in Annual Reports. Journal of Global Information Management, 27(4), 91-118. doi:10.4018/ JGIM.2019100105

Herold, D., \& Herold, D. M. (2018). Has Carbon Disclosure Become More Transparent in the Global Logistics Industry? An Investigation of Corporate Carbon Disclosure Strategies Between 2010 and 2015. Logistics, 2(3), 13. doi:10.3390/logistics2030013

Herold, D., Lee, K.-H., Herold, D. M., \& Lee, K.-H. (2017). The Influence of the Sustainability Logic on Carbon Disclosure in the Global Logistics Industry: The Case of DHL, FDX and UPS. Sustainability, 9(4), 601. doi:10.3390/su9040601

Hertz, S., \& Alfredsson, M. (2003). Strategic development of third party logistics providers. Industrial Marketing Management, 32(2), 139-149. doi:10.1016/S0019-8501(02)00228-6

Hirota, S., Kubo, K., Miyajima, H., Hong, P., \& Won Park, Y. (2010). Corporate mission, corporate policies and business outcomes: Evidence from Japan. Management Decision, 48(7), 1134-1153. doi:10.1108/00251741011068815

Hofmann, E., \& Osterwalder, F. (2017). Third-Party Logistics Providers in the Digital Age: Towards a New Competitive Arena? Logistics, 1(2), 9. doi:10.3390/logistics1020009

Hong, P., Hirota, S., Won Park, Y., Kubo, K., \& Miyajima, H. (2010). Corporate mission, corporate policies and business outcomes: Evidence from Japan. Management Decision, 48(7), 1134-1153. doi:10.1108/00251741011068815

Hutton, R. B., Cox, D. B., Clouse, M. L., Gaensbaur, J., \& Banks, B. D. (2006). The role of sustainable development in risk assessment and management for multinational corporations. Academic Press. 
Jandaghi, G. (2011). A Content Analysis of the Mission Statements of Iranian Joint Stock Firms in Four Industries: A further research to explore the implications of Peyrefitte \& David (2006) findings. Academic Leadership: The Online Journal, 9(2). https://scholars.fhsu.edu/alj/vol9/iss2/2

Johnson, G., Scholes, K., \& Whittington, R. (2008). Exploring Corporate Strategy (8th ed.). Prentice Hall.

Jung, H. (2017). Evaluation of Third Party Logistics Providers Considering Social Sustainability. Sustainability, 9(5), 777. doi:10.3390/su9050777

Karia, N., Wong, C. Y., Asaari, M. H. A. H., \& Lai, K.-H. (2015). The Effects of Resource Bundling on ThirdParty Logistics Providers' Performance. International Journal of Engineering Business Management, 7, 9. doi:10.5772/60041

Kemp, S., \& Dwyer, L. (2003). Mission statements of international airlines: A content analysis. Tourism Management, 24(6), 635-653. doi:10.1016/S0261-5177(03)00049-9

Khalili, N. R., Duecker, S., Ashton, W., \& Chavez, F. (2015). From cleaner production to sustainable development: The role of academia. Journal of Cleaner Production, 96, 30-43. doi:10.1016/j.jclepro.2014.01.099

King, D. L., Case, C. J., \& Premo, K. M. (2014). An international mission statement comparsion: United States, France, Germany, Japan, and China. Academic Press.

Klemm, M., Sanderson, S., \& Luffman, G. (1991). Mission statements: Selling corporate values to employees. Long Range Planning, 24(3), 73-78. doi:10.1016/0024-6301(91)90187-S PMID:10112154

Kumar, A. (2008). From mass customization to mass personalization: A strategic transformation. International Journal of Flexible Manufacturing Systems, 19(4), 533-547. doi:10.1007/s10696-008-9048-6

Law, K. M. Y., \& Breznik, K. (2018). What do airline mission statements reveal about value and strategy? Journal of Air Transport Management, 70, 36-44. doi:10.1016/j.jairtraman.2018.04.015

Law, K. M. Y., \& Gunasekaran, A. (2012). Sustainability development in high-tech manufacturing firms in Hong Kong: Motivators and readiness. International Journal of Production Economics, 137(1), $116-125$. doi:10.1016/j.ijpe.2012.01.022

Li, X. (2014). Operations Management of Logistics and Supply Chain: Issues and Directions. Discrete Dynamics in Nature and Society, 2014, 1-7. Advance online publication. doi:10.1155/2014/701938

Linton, J. D., Klassen, R., \& Jayaraman, V. (2007). Sustainable supply chains: An introduction. Journal of Operations Management, 25(6), 1075-1082. doi:10.1016/j.jom.2007.01.012

Lyons, H., \& Sufi, T. (2003). Mission statements exposed. International Journal of Contemporary Hospitality Management, 15(5), 255-262. doi:10.1108/09596110310482173

Malbašić, I., Marimon, F., \& Mas-Machuca, M. (2016). Is it worth having focused values? Management Decision, 54(10), 2370-2392. doi:10.1108/MD-05-2016-0282

Margolis, J. D., \& Walsh, J. P. (2001). People and Profits?: The Search for A Link Between A Company's Social and Financial Performance (1st ed.). Psychology Press. doi:10.4324/9781410600622

Marz, J. W., Powers, T. L., \& Queisser, T. (2003). Corporate and Individual Influences on Managers' Social Orientation. Journal of Business Ethics, 46(1), 1-11. doi:10.1023/A:1024795705173

Mirvis, P., Googins, B., \& Kinnicutt, S. (2010). Vision, mission, values. Organizational Dynamics, 39(4), 316-324. doi:10.1016/j.orgdyn.2010.07.006

Nadarajah, G. S. (2015). Factors Influencing Third Party Logistics Performance in Malaysia: The Role of Trust as a Mediator. International Journal of Supply Chain Management, 4(4). http://ojs.excelingtech.co.uk/index. php/IJSCM/article/view/1154

Natek, S., \& Lesjak, D. (2013). Improving Knowledge Management by Integrating Hei Process and Data Models. Journal of Computer Information Systems, 53(4), 81-86. doi:10.1080/08874417.2013.11645653

Noorderhaven, N. G., Koen, C. I., \& Beugelsdijk, S. (2002). Organizational Culture and Network Embeddedness (No. 2002-91; Discussion Paper). Tilburg University, Center for Economic Research. https://ideas.repec.org/p/ tiu/tiucen/1c9b9347-6abe-4151-b48d-35c6de36a57e.html 
O'Brien, C. (1999). Sustainable production - a new paradigm for a new millennium. International Journal of Production Economics, 60-61, 1-7. doi:10.1016/S0925-5273(98)00126-1

Paarlberg, L. E., \& Perry, J. L. (2007). Values Management: Aligning Employee Values and Organization Goals. American Review of Public Administration, 37(4), 387-408. doi:10.1177/0275074006297238

Palmer, T. B., \& Short, J. C. (2008). Mission Statements in U.S. Colleges of Business: An Empirical Examination of Their Content With Linkages to Configurations and Performance. Academy of Management Learning \& Education, 7(4), 454-470. doi:10.5465/amle.2008.35882187

Pandey, I. M. (2015). Financial Management (11th ed.). Vikas Publishing House.

Pearce, J. A., \& David, F. (1987). Corporate Mission Statements: The Bottom Line. The Academy of Management Executive, 1(2), 109-115.

Persson, G., \& Virum, H. (2001). Growth Strategies for Logistics Service Providers: A Case Study. International Journal of Logistics Management, 12(1), 53-64. doi:10.1108/09574090110806226

Peyrefitte, J., \& David, F. R. (2006). A Content Analysis of the Mission Statements of United States Firms in Four Industries. International Journal of Management, 23(2), 296.

Porter, M. E. (1985). Technology and competitive advantage. The Journal of Business Strategy, 5(3), 60-78. doi:10.1108/eb039075

Quazi, A. M., \& O'Brien, D. (2000). An Empirical Test of a Cross-national Model of Corporate Social Responsibility. Journal of Business Ethics, 25(1), 33-51. doi:10.1023/A:1006305111122

R: The R Project for Statistical Computing. (2018). https://www.r-project.org/

Rojšek, I. (2001). From Red to Green: Towards the Environmental Management in the Country in Transition. Journal of Business Ethics, 33(1), 37-50. doi:10.1023/A:1011977116496

Rosenbeck, J. M., Wilson, A., \& Schneider, J. L. (2010). Pharmaceutical companies and sustainability: An analysis of corporate reporting. Benchmarking, 17(3), 421-434. doi:10.1108/14635771011049371

Semler, S. W. (1997). Systematic Agreement: A Theory of Organizational Alignment. Human Resource Development Quarterly, 8(1), 23-40. doi:10.1002/hrdq.3920080105

Serenko, A. (2013). Meta-analysis of scientometric research of knowledge management: Discovering the identity of the discipline. Journal of Knowledge Management, 17(5), 773-812. doi:10.1108/JKM-05-2013-0166

Stallworth Williams, L. (2008). The Mission Statement: A Corporate Reporting Tool With a Past, Present, and Future. Journal of Business Communication, 45(2), 94-119. doi:10.1177/0021943607313989

Sutcliffe, K. M., \& Vogus, T. J. (2003). Organizing For Resilience. Academic Press.

Taghi Alavi, M., \& Karami, A. (2009). Managers of small and medium enterprises: Mission statement and enhanced organisational performance. Journal of Management Development, 28(6), 555-562. doi:10.1108/02621710910959729

Thompson, A. A., \& Strickland, A. J. (2003). Strategic management concepts and cases (13th ed.). McGrawHill/Irwin. https://trove.nla.gov.au/work/9535819

Tosti, D., \& Jackson, S. (1994). Alignment: How it works and why it matters. Training : The Magazine of Manpower and Management Development, 31(4).

Waddock, S. A., \& Graves, S. B. (1997). The Corporate Social Performance-Financial Performance Link. Strategic Management Journal, 18(4), 303-319. doi:10.1002/(SICI)1097-0266(199704)18:4<303::AIDSMJ869>3.0.CO;2-G

Wang, K., Lu, H. C., Lee, R. C., \& Yeh, S.-Y. (2017). Knowledge Transfer, Knowledge-Based Resources, and Capabilities in E-Commerce Software Projects. Journal of Global Information Management, 25(3), 63-80. doi:10.4018/JGIM.2017070104

Weber, R. (1990). Basic Content Analysis. SAGE Publications, Inc., doi:10.4135/9781412983488 
Williams, R. I. Jr, Morrell, D. L., \& Mullane, J. V. (2014). Reinvigorating the mission statement through top management commitment. Management Decision. Advance online publication. doi:10.1108/MD-10-2012-0736

Wilson, I. (1992). Realizing the power of strategic vision. Long Range Planning, 25(5), 18-28. doi:10.1016/00246301(92)90271-3

Yu, M.-C., Wang, C.-N., \& Ho, N.-N.-Y. (2016). A Grey Forecasting Approach for the Sustainability Performance of Logistics Companies. Sustainability, 8(9), 866. doi:10.3390/su8090866

Zhang, J., \& Hung Lau, K. (2006). Drivers and obstacles of outsourcing practices in China. International Journal of Physical Distribution \& Logistics Management, 36(10), 776-792. doi:10.1108/09600030610714599

\section{ENDNOTE}

$1 \quad$ Armstrong \& Associates, Inc. (2016). A\&A's Top 50 Global Third-Party Logistics Providers (3PLs) List Largest 3PLs Ranked by 2015 Logistics Gross Revenue/Turnover.

Kris M. Y. Law $(P h D)$ is currently an Associate Professor at the School of Engineering, Deakin University, Australia. Prior to her joining Deakin University, she was a Lecturer at the Department of Industrial and Systems Engineering, Hong Kong Polytechnic University. She currently also holds a Docentship (Adjunct Professorship) in the Department of Industrial Engineering and Management, Oulu University in Finland. She undertook a post-doctoral research scholarship and was a Visiting Researcher at the Graduate Institute of Industrial Engineering, National Taiwan University in 2009-2011. Her expertise lies in organizational learning and development, technology and innovation management, technology-based entrepreneurship, project management and engineering education. She has published in journals and edited several books in the areas of performance management, organizational learning, technology and knowledge management.

Kristijan Breznik is Associate Professor habilitated in Mathematics and Research Methodology at the International School for Social and Business Studies in Celje, Slovenia. His main research interests, beside social network analysis, are data analysis, graph theory, database development, entrepreneurial networks as well as sport statistics. Currently, he is Editor-in-chief of International Journal of Management, Knowledge and Learning and member of the Editorial Boards of some prominent journals.

Andrew W. H. Ip $(P h D)$ has more than 30 years of experience in teaching, research, education, industry and consulting. He received his PhD from Loughborough University (U.K.), MBA from Brunel University (U.K.), MSc in Industrial Engineering from Cranfield University (U.K.), and LLB (Hons) from the University of Wolverhampton (U.K.). He is now Professor Emeritus Mechanical Engineering of University of Saskatchewan, and Principal Research Fellow in the Department of Industrial and Systems Engineering of The Hong Kong Polytechnic University. He is also visiting professor of various universities in Mainland China, and Honorary Industrial Fellow of the University of Warwick, Warwick Manufacturing Group, UK. Prof. Ip has published nearly 250 papers with over 150 papers in SCl indexed journals. He is also the Editor-in-Chief of Enterprise Information Systems (SCl Indexed), and the Editor-in-Chief and Founder of International Journal of Engineering Business Management (ESCI and SCOPUS Indexed). He is a senior member of the Institute of Electrical and Electronics Engineers (IEEE), and member of the Hong Kong Institution of Engineers (HKIE). 